\title{
Transpyloric fluid movement and antroduodenal motility in patients with gastro-oesophageal reflux
}

\author{
P M KING, A PRYDE, AND R C HEADING \\ From the Department of Medicine, Royal Infirmary, Edinburgh
}

SUMMARY The pattern of transpyloric fluid movement and associated antroduodenal motility was compared in patients with gastro-oesophageal reflux (GOR) and healthy controls using real time ultrasonic imaging. A similar number of cyclical periods of antroduodenal motor activity (GOR 94 and control 91) was studied in each group. Mean antral cycle times and the frequency of occurrence of related proximal duodenal contractions (antroduodenal coordination) were similar. Transpyloric fluid movement occurred as a number of discrete episodes in each cycle. Gastroduodenal flow was more frequent in the GOR group (mean $2 \cdot 7 \pm 0.4$ episodes per cycle) than in controls (mean $1 \cdot 7 \pm 0 \cdot 3)$. The mean duration of these episodes in both groups was similar at around 2.5 seconds. Duodenogastric flow (reflux) was observed in many cycles (GOR 63\%; controls 54\%), but there was no difference in the mean number of episodes per cycle (GOR 0.79 ; control 0.74 ) or their mean duration (two seconds for both). Transpyloric fluid flow only occurs when a pressure gradient is created across the open pylorus. These observations indicate that in GOR the gastroduodenal pressure gradient is positive more frequently than in normal controls. Gastroduodenal liquid flow but not duodenogastric reflux differs in GOR patients and controls.

Gastric emptying is reported to be altered in patients with gastro-oesophageal reflux (GOR) $)^{1.3}$ and in addition there have been studies suggesting that duodenogastric reflux might be important in the pathogenesis of reflux oesophagitis. ${ }^{+-1}$ We have used real time ultrasonic imaging to examine the pattern of fluid movement across the pylorus and the associated gastroduodenal motility in a group of patients with GOR and in normal controls.

\section{Methods \\ PATIENTS \\ Studies were carried out on 10 patients with gastro- oesophageal reflux (GOR) (five men, five women; mean age 54 years) and 10 normal volunteer subjects (five men, five women; mean age 29 years) as controls. The patients were initially contacted by letter and all gave their informed consent to the ultrasonic examination. All 10 patients had previously been shown to have abnormal reflux into the lower oesophagus by 24 hour $\mathrm{pH}$ probe \\ Address for correspondence: Mr P M King. Department of Medicine. Royal Intirmary. Edinburgh EH3 $9 \mathrm{YW}$. Scotland. \\ Received for publication 16 September 1986}

monitoring ${ }^{7}$ and all were symptomatic at the time of ultrasonic examination.

The subjects were studied after an overnight fast, including omission of any medication for at least 12 hours before the ultrasound examination. Each ingested a $500 \mathrm{ml}$ liquid test meal composed of $433.4 \mathrm{ml}$ water at $37^{\circ} \mathrm{C}$ to which was added $66.6 \mathrm{ml}$ diluting orange and $2.5 \mathrm{~g}$ sodium bicarbonate to bring the $\mathrm{pH}$ of the meal up to neutral $(\mathrm{pH} 7 \cdot 0)$. The test meal had an osmolarity of $285 \mathrm{mOsm} / \mathrm{l}$ and contained $0.5 \mathrm{~g}$ of the bran particles.

During ingestion of the test meal, which usually took around two minutes, and the subsequent 20 minutes, visualisation of the events at the gastroduodenal junction was achieved by ultrasonic scanning. The ultrasonic images were simultaneously recorded on to videotape and analysis undertaken on a section of the recorded events beginning as soon as possible after ingestion of the test meal, where a clear image of the distal antrum, pyloric canal and proximal duodenum was constantly maintained in conjunction with a sufficient concentration of bran particles suspended in the luminal contents to allow detection of transpyloric movement. The analysis was carried out by two independent observers who 
noted the timing and duration of contractions of the terminal antrum and proximal duodenum and also the occurrence of episodes of gastroduodenal (forward flow) and duodenogastric (retrograde flow) movement of particles across the pylorus. Contractions were timed from the point where the opposing terminal antral (immediate prepyloric area) or proximal duodenal (first part) walls began to occlude their respective lumena until the subsequent onset of relaxation when the lumena once more became visibly patent. Details of observer variability and the reproducibility of the results have been reported elsewhere."

Statistical comparisons were made using unpaired Student's $t$ test and these were taken to be significantly different if $\mathrm{p}<() \cdot() 1$.

\section{Results}

The sections of the ultrasonic recordings selected for analysis were taken from comparable times in the immediate postprandial period in the two groups of subjects. The analysed sections in the control group began $5 \cdot 1 \pm 2 \cdot 7$ (mean $\pm \mathrm{SD}$ ) minutes after ingestion of the test meal, while those in the GOR group began after $4.2 \pm 3.8$ minutes $(\mathrm{t}=() \cdot 62 ; \mathrm{NS})$ In all, around 90 cyclical periods of gastroduodenal motor activity were observed in each group (control 91, GOR 94).

The pattern of gastroduodenal motor activity observed in each group was similar. Table 1 shows the mean gastric cycle times and the ratio of related contractions of the proximal duodenum to terminal antral contractions of each subject. The overall gastric cycle time in the control group was $21 \cdot 3 \pm 2 \cdot 4$ seconds and was almost identical to that of the GOR group which was $21 \cdot 3 \pm 2 \cdot 5$. The ratio of contractions of the proximal duodenum to those of the terminal

Table 1 Mean gastric cycle times (seconds) and ratio of proximal duodenal to terminal antral contractions

\begin{tabular}{|c|c|c|c|c|}
\hline \multirow[b]{2}{*}{ Subject } & \multicolumn{2}{|l|}{ Control } & \multicolumn{2}{|l|}{$G O R$} \\
\hline & $\begin{array}{l}\text { Mean cycle } \\
\text { time } \pm S I)\end{array}$ & $\begin{array}{l}D C / T A C \\
\text { ratio }^{*}\end{array}$ & $\begin{array}{l}\text { Mean cycle } \\
\text { time } \pm S D\end{array}$ & $\begin{array}{l}D C / T A C \\
\text { ratio }^{*}\end{array}$ \\
\hline 1 & $22 \cdot 3 \pm 2 \cdot 9$ & 0.64 & $23 \cdot 5 \pm 2 \cdot 7$ & $(0.82$ \\
\hline 2 & $26 \cdot 6 \pm 2 \cdot 3$ & 0.57 & $19.8 \pm 3.9$ & 0.67 \\
\hline 3 & $22 \cdot 5 \pm 2 \cdot 7$ & 0.38 & $21 \cdot() \pm 1 \cdot 1$ & $1 \cdot()$ \\
\hline 4 & $18 \cdot 8 \pm 2 \cdot 3$ & 0.69 & $24 \cdot 3 \pm 2 \cdot 8$ & 0.56 \\
\hline 5 & $17 \cdot 5 \pm 2 \cdot()$ & $(0 \cdot 60$ & $21 \cdot 3 \pm 4 \cdot 2$ & 0.83 \\
\hline 6 & $20 \cdot 2 \pm 4 \cdot 1$ & 0.36 & $25 \cdot 6 \pm 1 \cdot 7$ & 0.78 \\
\hline 7 & $21 \cdot 5 \pm 2 \cdot 6$ & $(0 \cdot 70$ & $18 \cdot 0 \pm 1 \cdot 4$ & 0.17 \\
\hline 8 & 2()$\cdot 3 \pm 2 \cdot 4$ & $(0.56$ & $20 \cdot 3 \pm 3 \cdot 8$ & $(0.67$ \\
\hline 9 & $21.9 \pm 1.8$ & 0.50 & 2()$\cdot 1 \pm 2 \cdot 3$ & 0.50 \\
\hline 10 & $20 \cdot 7 \pm 2 \cdot 2$ & 0.92 & $18.7 \pm 4 \cdot 3$ & 0.58 \\
\hline
\end{tabular}

* Ratio of contractions of the proximal duodenum to those of the terminal antrum.
Table 2 Pattern of episodes of gastroduodenal flow

\begin{tabular}{|c|c|c|c|c|}
\hline Subject & $\begin{array}{l}\text { Cycles with } \\
\text { episodes (\%) }\end{array}$ & $\begin{array}{l}\text { Duration of of } \\
\text { episodes } \\
\text { (Mean } \pm S D) \text { ) }\end{array}$ & $\begin{array}{l}\text { Episodes } \\
\text { cycle }(n) \\
\text { (Me(an } \pm S D)\end{array}$ & $\begin{array}{l}\% \text { Episodes } \\
\text { occurring } \\
\text { shortly after } \\
\text { TAC }(\%)\end{array}$ \\
\hline Control & 96 & $2 \cdot 8 \pm 0.7$ & $1.7 \pm 11 \cdot 4$ & 66 \\
\hline GOR & $1(x)$ & $2 \cdot 3 \pm 0.4$ & $2.7 \pm 0.3$ & 62 \\
\hline
\end{tabular}

*Seconds: TAC - terminal antral contraction.

antrum was also similar in the two groups (control $0 \cdot 60 \pm 0 \cdot 16$, GOR $0 \cdot 66 \pm(0 \cdot 23)$.

Transpyloric fluid movement occurred in both groups as intermittent brief episodes when the pylorus was patent. The timing of occurrence and the duration of the individual episodes was obtained from the chart plots of the 10 subjects in each group.

The pattern of episodes of gastroduodenal flow is summarised in Table 2. Gastroduodenal flow was observed in $96 \%$ of cycles in the controls and in all cycles in the GOR group. Significantly more episodes of gastroduodenal flow occurred in each cycle in the GOR group than in controls $(t=6.4 ; p<0 \cdot()(0) 1)$. The mean duration of these episodes in both groups, however, was no different and was around 2.5 seconds. Over $60 \%$ of episodes of gastroduodenal fluid movement occurred within five seconds (controls $4.9 \pm 1.1$ seconds; GOR $5.3 \pm 1.3$ seconds) after relaxation of the pylorus and terminal antrum.

The pattern of duodenogastric flow (reflux) is shown in Table 3. The episodes were observed in many cycles in both the control and GOR groups, but there was no difference in their mean duration or the mean number of episodes per cycle. The majority of these episodes of duodenogastric flow (control $66 \%$, GOR $63 \%$ ) occurred within five seconds (controls $5.5 \pm 2.5$ seconds; GOR $4.6 \pm 1.6$ seconds) before the terminal antral contraction.

\section{Discussion}

In this study using real time ultrasonic imaging to examine the moment to moment characteristic of

Table 3 Pattern of episodes of duodenogastric flow

\begin{tabular}{|c|c|c|c|c|}
\hline Subject & $\begin{array}{l}\text { Cycles with } \\
\text { episodes (\%) }\end{array}$ & $\begin{array}{l}\text { Duration }{ }^{*} \text { of } \\
\text { episodes } \\
\text { (Mean } \pm S D)\end{array}$ & $\begin{array}{l}\text { Episodes/ } \\
\text { cycle }(n) \\
\text { (Mean } \pm S D)\end{array}$ & $\begin{array}{l}\text { Episodes } \\
\text { occurring } \\
\text { shorlly before } \\
\text { TAC (n) }\end{array}$ \\
\hline Control & 54 & $2.1 \pm 0.5$ & $(1) \cdot 7 \pm 0.4$ & 66 \\
\hline GOR & 63 & $2 \cdot 1 \pm 0.5$ & $0.8 \pm 0.3$ & 6.3 \\
\hline
\end{tabular}

${ }^{*}$ Seconds: TAC - terminal antral contraction. 
transpyloric fluid movement during the early stages of the emptying of a liquid test meal in patients with GOR, a significant difference has been found in the pattern of this fluid movement when compared with normal subjects. Our observations do not directly reflect the volume of flow through the pylorus or the rate of gastric emptying but, because fluid movement (flow) can only occur in the presence of a pressure gradient between the lumen of the stomach and that of the duodenum, the results imply that in the patients with GOR this pressure gradient acts in a gastroduodenal direction more often than in controls. Although the average age of the GOR patients was greater than the controls, we know of no reason to believe this might explain the results.

The magnitude and direction of the pressure gradient across the pylorus depends on the relative intraluminal pressures in the stomach and proximal duodenum. ${ }^{411}$ Intragastric pressure is thought to be largely regulated by the tone of the gastric fundus and fundal tone is considered to be a prime factor in the emptying of liquids. ${ }^{12}$ This tone is influenced by the vagus nerve. ${ }^{13}$ Regulation of intraduodenal pressure is, however, poorly understood. Interruption of the inhibitory impulses from the vagus causes impairment of the ability of the fundus to relax and accommodate the volume of a meal and this effect is manifest as an increased rate of liquid emptying from the stomach of vagotomised subjects compared with normal controls. ${ }^{1+16}$

It has previously been suggested that the fibres of the vagus lying in direct contact with the oesophageal smooth muscle may be compromised by involvement in a panmural extension of the oesophagitis in GOR.' In a more recent study, however, vagal impairment in GOR was found not just to be confined to the gastrointestinal tract ${ }^{17}$ and the authors felt that vagal impairment was therefore unlikely to be simply a consequence of GOR and might in fact be important in its pathogenesis. If the vagal fibres to the gastric fundus are affected in patients with GOR, then the increase in number of gastroduodenal episodes of flow per gastroduodenal cycle seen in the GOR subjects in this study may reflect increased intragastric pressure caused by an impairment of gastric fundal relaxation.

The role of duodenogastric reflux in the pathogenesis of reflux oesophagitis in subjects with an intact stomach is unclear. Under experimental conditions, bile and pancreatic juice are injurious to the oesophageal mucosa ${ }^{1 \times 19}$ and in patients who have undergone gastric surgery bile can undoubtedly be a cause of oesophagitis."2 Several investigators who have studied duodenogastric reflux of bile in patients with symptomatic oesophagitis, found it to be significantly greater in these patients than in controls." ${ }^{21}$ In these studies duodenal or gastric intubation was utilised to permit the direct detection of refluxed material. In contrast, Little and coworkers, 2 who used an intragastric $\mathrm{pH}$ probe to monitor their patients for 24 hours, found a decreased frequency of alkaline duodenogastric reflux episodes. Matikainen and coworkers, however, who used non-invasive cholescintigraphy to detect duodenogastric reflux, found the incidence of reflux in controls and patients with GOR to be similar. ${ }^{23}$ A possible basis for these apparently conflicting results may lie with the suggestion that intubation itself may influence the results, ${ }^{2+35}$ and that reflux of duodenal contents and reflux of bile do not necessarily parallel each other..$^{26}$

Some duodenogastric reflux is a normal occurrence in healthy subjects ${ }^{27}$ and thus the presence of bile in the stomach cannot be considered pathological, as previously was widely believed, ${ }^{2 \times}$ but rather the demonstration of abnormal reflux will depend on the use of techniques which will allow it to be quantified. ${ }^{29}$ Our findings, using a non-invasive method, show that duodenogastric movement of fluid across the pylorus occurred in many gastroduodenal cycles and the pattern of the episodes was similar in the control and GOR groups.

Antroduodenal motility has not been extensively studied in GOR. In this investigation, the pattern and coordination of contractions of the terminal antrum and proximal duodenum observed during the emptying of a liquid test meal were similar in the GOR and control groups. These results conflict with those of Behar and Ramsby who used a perfused catheter system to measure antroduodenal contractility during the emptying of a semisolid meal and found a decreased number of antral contractions in patients with GOR compared with normal controls. ${ }^{3 \prime \prime}$ Antral contractile activity, however, probably plays little part during the emptying of liquid test meals from the stomach $^{12.3132}$ and it must therefore remain possible that the difference between the nature of the test meal used in this study and that of Behar and Ramsby is responsible for these conflicting results.

In conclusion, this study has shown that in GOR there is a significant alteration in the normal pattern of gastroduodenal, but not duodenogastric, fluid movement. The pattern of antroduodenal motility, however, remains normal.

\section{References}

1 Little AG, DeMeester TR, Kirchner PT, O'Sullivan GC, Skinner DB. Pathogenesis of oesophagitis in patients with gastroesophageal reflux. Surgery 1980; 88: 101-7.

2 McCallum RW, Berkowitz DM, Lerner E. Gastric emptying in patients with gastroesophageal reflux. Gastroenterology 1981; 80: 285-91. 
3 McCullum RW, Mensh R, Lange R. Definition of the gastric emptying abnormality present in gastroesophageal reflux patients. In: Weinbeck M, ed. Motility of the digestive tract. New York: Raven Press, 1982.

4 Gillison EW, de Castro VAM, Nyhus LM, Kusakari K, Bombeck CT. The significance of bile in reflux esophagitis. Surg Gynecol Obstet 1972; 134: 419-24.

5 Kaye MD, Showalter P. Pyloric incompetence in reflux esophagitis. Clin Res 1972; 20: 733.

6 Stol DV, Murphy GM, Collis JL. Duodeno-gastric reflux and acid secretion in patients with symptomatic hiatal hernia. Scand J Gastroenterol 1974; 9: 97-101.

7 DeMeester TR, Wang CI, Wernly JA, et al. Technique, indications and clinical use of 24 hour esophageal $\mathrm{pH}$ monitoring. J Thorac Cardiovasc Surg 1980; 79: 656-70.

8 King PM, Adam RD, Pryde A, McDicken WN, Heading RC. Relationships of human antroduodenal motility and transpyloric fluid movement: non-invasive observations with real-time ultrasound. Gut 1984; 25: 1384-91.

9 Strunz UT, Grossman MI. Effect of intragastric pressure on gastric emptying and secretion. Am J Physiol 1978; 235: E552-5.

10 Rock E, Malmud L, Fisher RS. Motor disorders of the stomach. Med Clin N Am 1981; 65: 1269-89.

11 Weems WA. The intestine as a fluid propelling system. Rev Physiol 1981; 43: 9-19.

12 Kelly KA. Gastric emptying of liquids and solids: roles of proximal and distal stomach. Am J Physiol 1980; 239: G71-G6.

13 Jahnberg T. Gastric adaptive relaxation. Scand $J$ Gastroenterol 1977; 46: 1-32.

14 Aune S. Intragastric pressure after vagotomy in man. Scand J Gastroenterol 1969; 4: 447-52.

15 Koster N, Madsen $\mathrm{P}$. The intragastric pressure before and immediately after truncal vagotomy. Scand $J$ Gastroenterol 1970; 5: 381-3.

16 Stadaas J. Intragastric pressure/volume relationship. A clinical and experimental study. Universitets-forlaget, Oslo: Thesis, 1974.

17 Ogilvie AL, James PD, Atkinson M. Impairment of vagal function in reflux oesophagitis. $Q J$ Med 1985; 54: 61-74.
18 Helsingen N. Oesophagitis following total gastrectomy in rats. Acta Chir Scand 1960; 119: 230-45.

19 Moffat RC, Berkas EM. Bile esophagitis. Arch Surg 1965; 91: 963-6.

20) Windsor CWD. Gastroesophageal reflux after partial gastrectomy. Br Med J 1967; 2: 1233-4.

21 Gillison EW, Capper WM, Airth GR, Gibson MJ, Bradford I. Hiatus hernia and heartburn. Gut 1969; 10: 609-13.

22 Little AG, Martinez EI, DeMeester TR, Blough RM, Skinner DB. Duodenogastric reflux and reflux esophagitis. Surgery 1984; 96: 447-54.

23 Matikainen M, Taavitsainen M, Kalima TV. Duodenogastric reflux in patients with heartburn and oesophagitis. Scand J Gastroenterol 1981; 16: 253-5.

24 Tolin RD, Malmud LS, Stelzer F, et al. Enterogastric reflux in normal subjects and in patients with Billroth II gastroenterostomy. Gastroenterology 1979; 77: 1027-33.

25 Muller-Lissner SA, Fimmel CJ, Will N, Muller-Duysing W, Heinzel F, Blum A. Effect of gastric and transpyloric tubes and gastric emptying and duodenogastric reflux. Gastroenterology 1982; 83: 1276-9.

26 Muller-Lissner SA, Fraass C. Dissociation of duodenogastric marker reflux and bile salt reflux. Dig $\mathrm{Dis} S \mathrm{Si}$ 1985; 30: 733-8.

27 Muller-Lissner SA, Fimmel CJ, Sonnenberg A, et al. Novel approach to quantify duodenogastric reflux in healthy volunteers and in patients with type I gastric ulcer. Gut 1983; 24: 510-8.

28 Rokkjaer M. Some aspects of intestino-gastric reflux. Dan Med Bull 1980; 27: 185-202.

29 Heading RC. Duodenogastric reflux. Gut 1983; 24: 507-9.

30 Behar J, Ramsby G. Gastric emptying and antral motility in reflux esophagitis: effect of oral metoclopramide. Gastroenterology 1978; 74: 253-6.

31 Dozois RR, Kelly KA, Code CF. Effect of distal antrectomy on gastric emptying of liquids and solids. Gastroenterology 1971; 61: 675-81.

32 Meyer JH. Gastric emptying of ordinary food: effect of antrum on particle size. Am J Physiol 1980; 239: G133-G5. 